\title{
Oral bisphosphonates in a postmenopausal population: a systemic review study
}

\author{
This article was published in the following Dove Press journal: \\ Open Access Surgery \\ 10 October 2013 \\ Number of times this article has been viewed
}

\section{Chia-Chi Chu \\ Hirofumi Haga}

Bundaberg Hospital, Bundaberg, Queensland, Australia
Correspondence: Chia-Chi Chu 2/2 Hidcote Rd, Campbelltown, Sydney, NSW 2560, Australia

Email subthalamic@gmail.com
Background: Osteoporosis is a debilitating disease that contributes to 1.5 million fractures per annum among women in the USA. The aim of this systemic review study was to determine the effects of oral bisphosphonates in preventing osteoporotic fractures in postmenopausal women.

Methods: A literature search was performed of the MEDLINE ${ }^{\circledR}$, Embase, and CENTRAL databases. Three types of oral bisphosphonates were identified for the study: alendronate, risedronate, and ibandronate. The chief outcome measure was the incidence of fractures in postmenopausal women.

Results: Five randomized controlled studies were included in the meta-analysis. A total of 9,941 patients received oral bisphosphonate, while 5,956 patients received a placebo. The overall risk ratio for all fracture events was 0.73 (confidence interval: 0.66-0.81) There was no significant increased risk for upper gastrointestinal side effects in patients taking bisphosphonates (odds ratio: 1.00; confidence interval: 0.92-1.08).

Conclusion: Oral bisphosphonates are associated with a statistically significant reduction in fracture risk in postmenopausal women. Adverse effects were similar for both placebo and oral bisphosphonates.

Keywords: osteoporosis, fractures, alendronate, risedronate, ibandronate, fracture risk

\section{Introduction}

Osteoporosis is a common disorder that contributes to about 1.5 million fractures per annum among women in the USA. ${ }^{1}$ Up to $50 \%$ of women will sustain at least one osteoporotic fracture during their lifetime. ${ }^{2}$ This debilitating condition has significant implications for public health. ${ }^{3}$ The most common consequences of osteoporosis are wrist, hip, and vertebral fractures. ${ }^{4}$ It is evident that the major source of morbidity and mortality in patients with osteoporosis is related to hip fractures.

The use of bisphosphonates has been important in treating postmenopausal osteoporosis. It reduces osteoclast-mediated bone resorption, which results in a reduction in bone turnover, an increase in bone mineral density (BMD), and a decrease in fracture risk. ${ }^{5}$ Alendronate has a half-life of 10.5 years, which is similar to that of bone mineral. ${ }^{6}$ The effects of bisphosphonates last for many years, even after treatment is ceased. The duration and magnitude of these effects are unknown. Treatment for osteoporosis often continues indefinitely.

Few fracture-risk studies have examined the long-term safety profile of bisphosphonate treatment. One study supported the long-term use of alendronate by demonstrating no increased fracture risk over 10 years. $^{7}$ In contrast, some reports have found that 
regular administration of bisphosphonates is associated with adverse gastrointestinal events, and oral bisphosphonates are associated with low intestinal absorption. ${ }^{8}$ Although several meta-analysis studies have examined individual oral bisphosphonates such as alendronate, ibandronate, or risedronate, few studies have analyzed these drugs collectively in one meta-analysis. ${ }^{7,8}$ The aim of this systematic review was to determine the effects of oral bisphosphonates in preventing osteoporotic fractures in postmenopausal women as well as to define the benefits and risks of oral bisphosphonates in postmenopausal women and to identify areas for future research.

\section{Methods}

The principal outcome measure in this study was the incidence of fractures, including wrist, hip, and vertebral fractures (morphometric and clinical fractures). Skull, pathological, and excessive trauma fractures were excluded. Only postmenopausal women were included in the studies, which included both primary and secondary prevention trials. The intervention groups receiving one of the oral bisphosphonates were compared with the control groups that received no treatment. Full-published articles in English were considered.

\section{Type of studies}

Randomized controlled trials with duration of at least 1 year were included in the review.

\section{Study population}

The study population consisted of postmenopausal women with osteoporosis.

\section{Intervention}

The intervention of one study group using one of the following oral bisphosphonates: alendronate, ibandronate, or risedronate.

\section{Outcome measure}

The outcome measure was vertebral, nonvertebral, and hip fractures.

\section{Literature search}

The search of the literature was carried out in the MEDLINE ${ }^{\circledR}$, Embase, and CENTRAL databases.

Literature search for MEDLINE:

1. osteoporosis, postmenopausal/

2. osteoporosis/

3. osteoporosis.tw.
4. exp bone density/

5. or/2-4

6. menopause/

7. postmenopau\$.tw.

8. or/6-7

9. 5 and 8

10. 1 or 9

11. exp bone density conservation agents/tu [Therapeutic Use]

12. 10 and 11

13. clinical trial.pt.

14. randomized controlled trial.pt.

15. random $\$$.tw.

16. placebo\$.tw

17. or/13-16

18. 12 and 17

19. limit 18 to (English language and humans)

For each selected study, details of study design, study population, selection criteria, and fracture incidence were extracted. Two assessors examined articles generated from the search and identified potential eligible journal articles. This strategy ensured there was no bias in the selection of articles. Articles that satisfied the inclusion criteria were collected for further analysis (Figure 1).

Three types of oral bisphosphonates were identified in the search: alendronate, risedronate, and ibandronate. The risk difference was calculated using the statistics function in RevMan 5 (The Nordic Cochrane Centre, The Cochrane

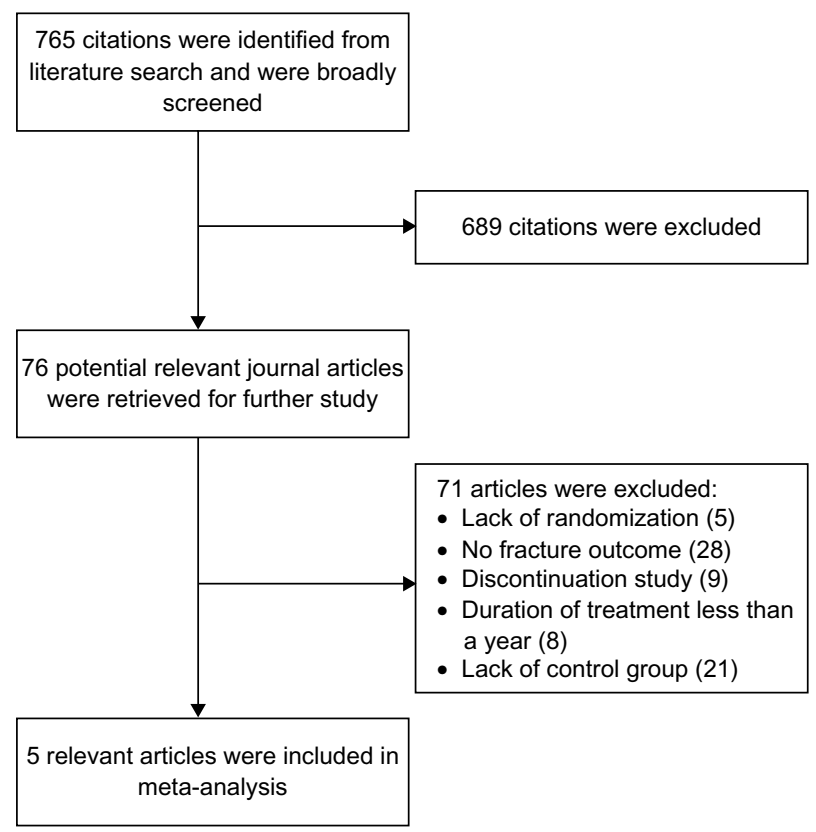

Figure I Flowchart illustrating the selection of articles for review. 
Collaboration, Copenhagen, Denmark), and the relative risk of fracture was calculated. The risk of upper gastrointestinal complications was compiled and compared across studies.

\section{Results}

The literature search retrieved 765 relevant articles, and 76 articles were retrieved for further study. A total of 71 studies were excluded for various reasons, including lack of fracture outcome, lack of randomization, and lack of control group. In the five studies included, 9,941 patients received oral bisphosphonate, and 5,956 patients received a placebo. Two trials examined the effects of alendronate, ${ }^{7,9}$ two trials examined the effects of risedronate, ${ }^{10,11}$ and one trial looked at ibandronate. ${ }^{12}$ Length of follow-up ranged from 2 to 5 years, and the mean age was 52 to 74 years.

\section{Trial characteristics}

The duration of therapy and dose of drug differed among the included studies. Black et al administered alendronate $5 \mathrm{mg}$ daily before increasing the dose to $10 \mathrm{mg}$ at 24 months. ${ }^{7}$ All patients were followed up for 3 years. A decade later, Black et al reinvestigated alendronate ( 5 or $10 \mathrm{mg}$ daily) in postmenopausal women for 5 years. ${ }^{9}$ Two studies examined risedronate: McClung et al treated patients with risedronate 2.5 or $5.0 \mathrm{mg}$ daily for 3 years, ${ }^{11}$ and Reginster et al conducted a multicentre study using risedronate of 2.5 or $5.0 \mathrm{mg}$ for three years. ${ }^{10}$ In contrast, Chesnut et al examined the effects of ibandronate $(2.5 \mathrm{mg}$ daily or $20 \mathrm{mg}$ intermittently) for 3 years. $^{12}$

\section{Effects of interventions}

Three trials evaluated fractures as the stated primary outcome. ${ }^{7,11,12}$ Nonvertebral fractures were reported in all five trials. ${ }^{7,9-12}$ Vertebral fractures were reported in four of the five studies. ${ }^{7,9-11}$ Hip fractures were reported in three studies. ${ }^{7,9,11}$ Four studies involved women with BMD and a high incidence of vertebral fractures..$^{7,9,11,12}$ The overall risk ratio for all fracture events was 0.73 (confidence interval [CI]: 0.66-0.81 [Figure 2]). All five trials demonstrated a reduction in fracture risk in patients taking bisphosphonates. The risk ratio ranged from 0.50 to $0.85,{ }^{9,12}$ which strongly favored oral bisphosphonates in reducing the fracture risk. Table 1 lists different relative risks for each fracture type. The data strongly favor bisphosphonates to prevent vertebral fractures, with a relative risk of 0.52 (CI: 0.46-0.60).

Adverse drug events were reported in four trials. ${ }^{7,10-12}$ In general, the reported adverse events were similar between placebo and the oral bisphosphonates. Four out of five trials reported upper gastrointestinal side effects in patients taking bisphosphonates. ${ }^{710-12}$ There was no significant increased risk for upper gastrointestinal side effects in patients taking bisphosphonates (odds ratio [OR]: 1.00; CI: 0.92-1.08 [Figure 3]). The OR ranged from 0.97 to 1.05 . $^{7,10,12}$

\section{Risk of bias in included studies}

The study by Black et al, in which allocation was concealed, was the only trial that achieved a loss to follow-up of $<5 \%{ }^{7}$ One trial had loss to follow-up from $5 \%$ to $20 \%,{ }^{7}$ whereas three trials had losses $>30 \% .^{10-12}$

\section{Discussion}

Osteoporotic fracture is associated with an increase in morbidity. Up to $50 \%$ of women do not return to their usual activities after sustaining a hip fracture. ${ }^{13}$ Oral bisphosphonates can potentially improve quality of life in patients with osteoporosis and might decrease mortality. They are associated with a reduction in fracture risk in postmenopausal women, based on the treatment of longest duration in the

\begin{tabular}{lrrrrr} 
& \multicolumn{2}{c}{ Experimental } & \multicolumn{2}{c}{ Control } \\
Study or subgroup & Events & Total & Events & Total & Weight \\
\hline 1 & 122 & 1022 & 148 & 1005 & $21.0 \%$ \\
2 & 76 & 1310 & 73 & 628 & $13.9 \%$ \\
3 & 89 & 750 & 140 & 752 & $19.7 \%$ \\
4 & 137 & 6197 & 95 & 3134 & $17.8 \%$ \\
5 & 208 & 662 & 162 & 437 & $27.5 \%$ \\
& & & & & \\
Total $(95 \%$ Cl) & & 9941 & & 5956 & $100.0 \%$ \\
Total events & 632 & & 618 & & \\
Heterogeneity: chi ${ }^{2}=11.04, d f=4(P=0.03) ; I^{2}=64 \%$ & \\
Test for overall effect: $Z=6.11(P<0.00001)$ &
\end{tabular}

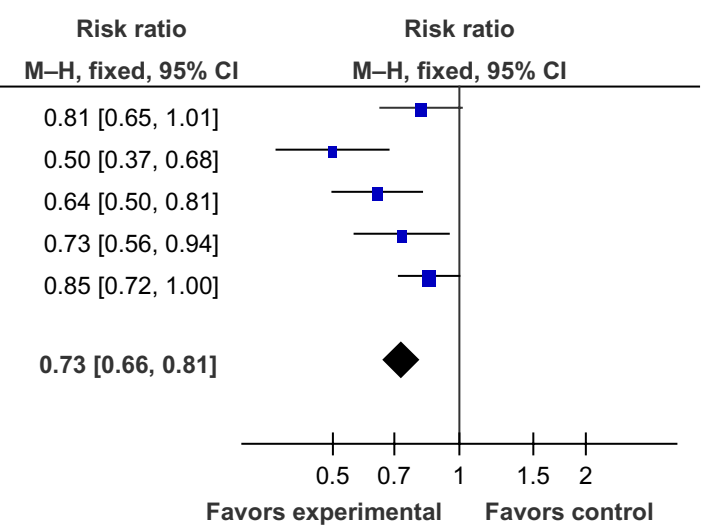

Figure 2 Bisphosphonates versus placebo - risk ratio of fractures. Abbreviations: $\mathrm{Cl}$, confidence interval; $\mathrm{M}-\mathrm{H}$, Mantel-Haenszel. 
Table I Relative risk for each fracture type

\begin{tabular}{llll}
\hline $\begin{array}{l}\text { Fracture } \\
\text { site }\end{array}$ & $\begin{array}{l}\text { Trials, } \\
\mathbf{n}\end{array}$ & $\begin{array}{l}\text { Participants, } \mathbf{n} \\
\text { (treatment/control) }\end{array}$ & $\begin{array}{l}\text { Relative } \\
\text { risk }(\mathbf{C I})\end{array}$ \\
\hline Vertebral & 4 & $5,673(3,297 / 2,376)$ & $0.52(0.46-0.60)$ \\
Nonvertebral & 3 & $3,938(2,090 / I, 848)$ & $0.85(0.73-1.00)$ \\
Hip & 3 & $12,493(7,88 I / 4,6 / 2)$ & $0.73(0.58-0.92)$ \\
Wrist & 2 & $3,126(I, 684 / I, 442)$ & $0.72(0.50-1.05)$ \\
\hline
\end{tabular}

Abbreviation: $\mathrm{Cl}$, confidence interval.

included studies. In addition, they demonstrated a preventative effect on osteoporotic fractures in postmenopausal women and are associated with a statistically significant reduction in vertebral, nonvertebral, wrist, and hip fractures. The findings are in keeping with those of Black et al, ${ }^{7}$ who demonstrated that the administration of alendronate is associated with a significant reduction in the risk of hip fractures among postmenopausal women in the community.

It is understood that, when bone containing bisphosphonate breaks down, the bisphosphonate recirculates both locally and systemically. The residual bisphosphonate continues to inhibit bone resorption, and the slow rate of bone resorption might be associated with the retention of bisphosphonates in bone after ceasing treatment. ${ }^{14}$ Further, most vertebral fractures have no symptoms and are not clinically detectable. Black et al found that only one-third of the radiographically defined vertebral fractures were detected clinically in the trial. The authors also demonstrated that alendronate therapy had similar effects on reducing the risk of radiographically defined and clinically detected vertebral fractures. ${ }^{7}$ Liberman and coworkers demonstrated that the administration of alendronate increased BMD at the spine and hip. ${ }^{15}$ However, their study did not have sufficient power to demonstrate the effect on nonvertebral fractures.
In our findings, there was no association between bisphosphonate treatment and an increased risk of upper gastrointestinal symptoms. Adverse effects were similar for both placebo and oral bisphosphonates. The overall OR for upper gastrointestinal adverse events was 1.00 (CI: 0.92-1.08), which confirmed the safety of using oral bisphosphonates. However, although no increased incidence of drug side effects was detected from the meta-analysis, risk of pathological hip fracture and upper gastrointestinal bleeding have been reported. Rare complications, such as osteonecrosis of the jaw, chiefly occur in cancer patients, and they are a serious complication of bisphosphonate treatment. This risk is very low in patients receiving oral bisphosphonates. ${ }^{16}$

\section{Limitations}

The results of this meta-analysis, based on a comprehensive literature review, are considered robust. However, these results are only as strong as the primary trials included in the review. Generalization of the findings is limited by the design of the included studies in the meta-analysis. The inclusion criteria for study participants were carefully chosen and, therefore, the effects of drugs in real life might vary considerably from those under the study conditions. Two assessors examined each title generated from the literature review and abstracted information using standardized data abstraction forms. A third independent reviewer verified the data to ensure inter-rater reliability. For statistical analysis, a fixed effects model was deemed appropriate because the assessment of residual deviance showed no detectable difference among fixed random effects assumptions. A potential limitation, on examining the drug-related adverse effects from meta-analyses, is that the patients in randomized controlled trials tend to be healthier. Therefore, the results

\begin{tabular}{lrrrrr} 
& \multicolumn{2}{c}{ Experimental } & \multicolumn{2}{c}{ Control } \\
Study or subgroup & Events & Total & Events & Total & Weight \\
\hline 1 & 422 & 1022 & 402 & 1005 & $18.8 \%$ \\
2 & 297 & 977 & 303 & 975 & $16.7 \%$ \\
3 & 203 & 815 & 104 & 407 & $8.2 \%$ \\
4 & 1347 & 6197 & 684 & 3134 & $56.2 \%$ \\
5 & 0 & 0 & 0 & 0 & \\
6 & 17 & 135 & 18 & 130 & $0.0 \%$ \\
Total (95\% Cl) & & & & & \\
Total events & 2269 & & 1493 & & \\
Heterogeneity: chi ${ }^{2}=0.53, d f=3(P=0.91) ;\left.\right|^{2}=0 \%$ \\
Test for overall effect: $Z=0.01(P=0.99)$ & &
\end{tabular}

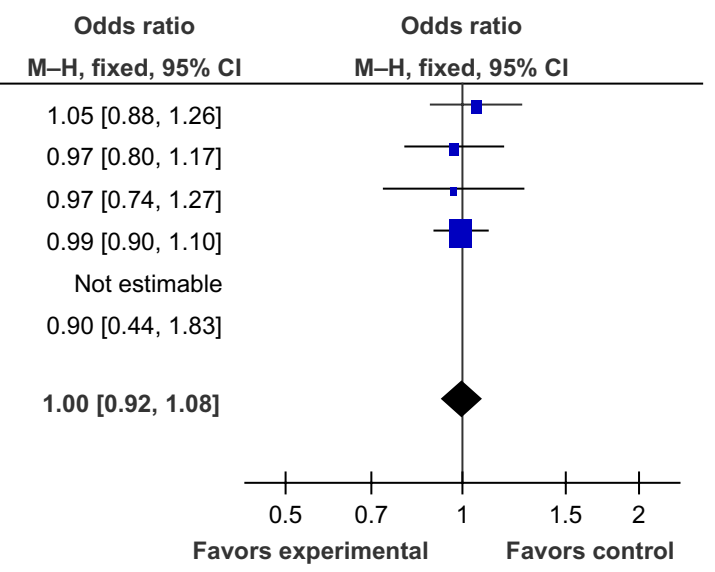

Figure 3 Bisphosphonates versus placebo - odds ratio of complications. Abbreviations: $\mathrm{Cl}$, confidence interval; $\mathrm{M}-\mathrm{H}$, Mantel-Haenszel. 
might not reflect true clinical practice. In addition, there was a difference in the study period among the included trials, which varied from 1 to 5 years. One study used two different doses in examining the effects of ibandronate, which added heterogeneity to the meta-analysis. ${ }^{12}$ Another potential source of heterogeneity is the disagreement on the definition of "nonvertebral fracture." Some researchers might include any fracture other than vertebral fracture, whereas others might consider only fractures of the clavicle, humerus, wrist, pelvis, hip, or leg.

\section{Conclusion}

Our results show that oral bisphosphonates (alendronate, risedronate, and ibandronate) are safe and effective in preventing fractures in postmenopausal women.

\section{Disclosure}

The authors declare no conflicts of interest in this work.

\section{References}

1. Riggs BL, Melton LJ 3rd. The prevention and treatment of osteoporosis. N Engl J Med. 1992;327(9):620-627.

2. Jones G, Nguyen T, Sambrook PN, Kelly PJ, Gilbert C, Eisman JA. Symptomatic fracture incidence in elderly men and women: the Dubbo Osteoporosis Epidemiology Study (DOES). Osteoporos Int. 1994;4(5):277-282.

3. Barrett-Connor E. The economic and human costs of osteoporotic fracture. Am J Med. 1995;98(2A):3S-8S.

4. Hodsman AB, Hanley DA, Josse R. Do bisphosphonates reduce the risk of osteoporotic fractures? An evaluation of the evidence to date. CMAJ. 2002;166(11):1426-1430.

5. Watts NB, Harris ST, Genant HK, et al. Intermittent cyclical etidronate treatment of postmenopausal osteoporosis. $N$ Engl J Med. 1990;323(2):73-79.
6. Rodan G, Reszka A, Golub E, Rizzoli R. Bone safety of long-term bisphosphonate treatment. Curr Med Res Opin. 2004;20(8):1291-1300.

7. Black DM, Cummings SR, Karpf DB, et al. Randomised trial of effect of alendronate on risk of fracture in women with existing vertebral fractures. Fracture Intervention Trial Research Group. Lancet. 1996;348(9041):1535-1541.

8. Ettinger B, Pressman A, Schein J. Clinic visits and hospital admissions for care of acid-related upper gastrointestinal disorders in women using alendronate for osteoporosis. Am J Manag Care. 1998;4(10): 1377-1382.

9. Black DM, Schwartz AV, Ensrud KE, et al; FLEX Research Group. Effects of continuing or stopping alendronate after 5 years of treatment: the Fracture Intervention Trial Long-term Extension (FLEX): a randomized trial. JAMA. 2006;296(24):2927-2938.

10. Reginster J, Minne HW, Sorensen OH, et al. Randomized trial of the effects of risedronate on vertebral fractures in women with established postmenopausal osteoporosis. Vertebral Efficacy with Risedronate Therapy (VERT) Study Group. Osteoporos Int. 2000;11(1):83-91.

11. McClung MR, Geusens P, Miller PD, et al; Hip Intervention Program Study Group. Effect of risedronate on the risk of hip fracture in elderly women. Hip Intervention Program Study Group. $N$ Engl $J$ Med. 2001;344(5):333-340.

12. Chesnut CH 3rd, Skag A, Christiansen C, et al; Oral Ibandronate Osteoporosis Vertebral Fracture Trial in North America and Europe (BONE). Effects of oral ibandronate administered daily or intermittently on fracture risk in postmenopausal osteoporosis. $J$ Bone Miner Res. 2004;19(8):1241-1249.

13. Brown JP, Josse RG; Scientific Advisory Council of the Osteoporosis Society of Canada. 2002 clinical practice guidelines for the diagnosis and management of osteoporosis in Canada. CMAJ. 2002; 167(Suppl 10):S1-S34.

14. Bone HG, Hosking D, Devogelaer JP, et al; Alendronate Phase III Osteoporosis Treatment Study Group. Ten years' experience with alendronate for osteoporosis in postmenopausal women. $N$ Engl J Med. 2004;350(12):1189-1199.

15. Liberman UA, Weiss SR, Bröll J, et al. Effect of oral alendronate on bone mineral density and the incidence of fractures in postmenopausal osteoporosis. The Alendronate Phase III Osteoporosis Treatment Study Group. N Engl J Med. 1995;333(22):1437-1443.

16. Woo SB, Hellstein JW, Kalmar JR. Narrative [corrected] review: bisphosphonates and osteonecrosis of the jaws. Ann Intern Med. 2006;144(10):753-761.
Open Access Surgery

\section{Publish your work in this journal}

Open Access Surgery is an international, peer-reviewed, open access journal that focuses on all aspects of surgical procedures and interventions. Patient care around the peri-operative period and patient outcomes post surgery are key topics. All grades of surgery from minor cosmetic interventions to major surgical procedures are covered. Novel techniques

\section{Dovepress}

and the utilization of new instruments and materials, including implants and prostheses that optimize outcomes constitute major areas of interest. The manuscript management system is completely online and includes a very quick and fair peer-review system. Visit http://www.dovepress.com/ testimonials.php to read real quotes from published authors. 